\title{
A Study of the Lateral Stability of Self-Propelled Fruit Harvesters
}

\author{
Maurizio Cutini ${ }^{1, *}$ (D), Massimo Brambilla ${ }^{1}$ (D), Carlo Bisaglia ${ }^{1}$ (1), Stefano Melzi ${ }^{2}$, \\ Edoardo Sabbioni $^{2}$, Michele Vignati ${ }^{2}$ (D), Eugenio Cavallo ${ }^{3}$ and Vincenzo Laurendi ${ }^{4}$ \\ 1 CREA Research Centre for Engineering and Agro-Food Processingvia Milano 43, 24047 Treviglio, Italy; \\ massimo.brambilla@crea.gov.it (M.B.); carlo.bisaglia@crea.gov.it (C.B.) \\ 2 Politecnico di Milano Department of Mechanical Engineering, via La Masa 1, 20156 Milan, Italy; \\ stefano.melzi@polimi.it (S.M.); edoardo.sabbioni@polimi.it (E.S.); michele.vignati@polimi.it (M.V.) \\ 3 National Research Council (CNR) of Italy, Institute for Agricultural and Earthmoving \\ Machines (IMAMOTER), Strada delle Cacce, 73, 10135 Torino, Italy; eugenio.cavallo@cnr.it \\ 4 INAIL, Dipartimento Innovazioni Tecnologiche e Sicurezza degli Impianti, Prodotti e Insediamenti \\ Antropici (DITSIPIA), P.le Pastore 6, 00144 Rome, Italy; v.laurendi@inail.it \\ * Correspondence: maurizio.cutini@crea.gov.it; Tel.: +39-0363-49603
}

Received: 31 August 2017; Accepted: 30 October 2017; Published: 1 November 2017

\begin{abstract}
Self-propelled fruit harvesters (SPFHs) are agricultural machines designed to facilitate fruit picking and other tasks requiring operators to stay close to the foliage or to the upper part of the canopy. They generally consist of a chassis with a variable height working platform that can be equipped with lateral extending platforms. The positioning of additional masses (operators, fruit bins) and the maximum height of the platform (up to three meters above the ground) strongly affect machine stability. Since there are no specific studies on the lateral stability of SPFHs, this study aimed to develop a specific test procedure to fill this gap. A survey of the Italian market found 20 firms manufacturing 110 different models of vehicles. Observation and monitoring of SPFHs under real operational conditions revealed the variables mostly likely to affect lateral stability: the position and mass of the operators and the fruit bin on the platform. Two SPFHs were tested in the laboratory to determine their centre of gravity and lateral stability in four different settings reproducing operational conditions. The test setting was found to affect the stability angle. Lastly, the study identified two specific settings reproducing real operational conditions most likely to affect the lateral stability of SPFHs: these should be used as standard, reproducible settings to enable a comparison of results.
\end{abstract}

Keywords: safety; tiltable platform; rollover angle; agriculture

\section{Introduction}

Self-propelled fruit harvesters (SPFHs) are agricultural machines designed to work on unimproved natural or disturbed terrain [1]. They are intended to facilitate fruit picking and pruning, as well as any other task requiring operators to keep close to the foliage or to the upper part of the canopy. They replace ladders, so that workers are no longer required to carry them through the orchard and climb up and down; these saves time and work, thereby improving farm labour productivity [2] and operator safety [3].

Usually intended to carry at least two persons, the harvesters generally consist of a chassis, with a variable height work platform that can be equipped with lateral extending platforms enabling operators to reach fruiting branches more easily. Although SPFHs are usually powered by diesel engines, electrical engines have been introduced recently; they provide power both to the propulsion system and to the platform height and width adjusting mechanisms. The driving and operating console is located on the work platform; from this position operators can drive the machine forward 
or in reverse and adjust the platform height and width. During operations the machine runs on the natural ground surface, both flat and moderately inclined, and in the space between orchard rows at low operational speeds (approx. $0.4 \mathrm{~km} \mathrm{~h}^{-1}$ ). When the machine moves away from the orchards it runs at higher speeds, usually not exceeding $15 \mathrm{~km} \mathrm{~h}^{-1}$.

SPFHs can be equipped with various additional components such as self-levelling systems (to compensate for ground slope and keep the platform in a horizontal position), bin elevators and rails, different heights for front and rear or left and right portions of the platform, fruit picking assistance systems, and pneumatic or electric pruning systems.

Although the use of picking platforms has helped reduce workers' exposure to fall hazards and to risk factors associated with musculoskeletal disorders [3], operators are exposed to specific risks. For example, the French Mutualité Sociale Agricole, the second largest social security agency in France, recorded 325 accidents involving SPHFs from 2002 to 2009 and two deaths between 1995 and 2009, one following the machine's loss of stability when working on a road shoulder [4].

The positioning of additional masses (operators, fruit bins) and the maximum height of the platform (up to three meters above the ground) strongly affect machine stability. In particular, when running on unpaved ground and the lateral platform extended on one side only with the operators working on that side, the lateral displacement of the centre of gravity (CoG) may jeopardize the machine's stability even when standing still or moving slowly. The loss of machine stability cannot be effectively prevented: rollover protective structure (ROPS) would make the machine unsuitable for its intended purpose, and the possible operator error in tilt angle estimates make any recommendations about the maximum admissible operating gradient futile [5,6].

The literature contains a large number of studies on the stability of agricultural vehicles and related risks for operators [7-14], but very few address how to mitigate operator risks in relation with the loss of SPFH stability [4]. According to a survey of France the internal market for SPFHs is estimated at approximately 300-400 new machines sold per year, compared to 1500 to 2000 in Italy [4]. The figures on the French market are similar to the annual sales of large square balers, grape-pickers, and straddle tractors [4].

This the study aimed to help address SPFH safety issues by developing a procedure for assessing the lateral stability of these widely used agriculture vehicles under different working conditions.

\section{Materials and Methods}

The study involved a SPHF market survey, a collection of field data on real SPFH working conditions, and laboratory tests on representative SPFH components in settings reproducing real working conditions so has to define a procedure for assessing the lateral stability of these vehicles.

\subsection{Market Survey}

A survey of the Italian market was carried out by attending fairs and conducting telephone interviews. Technical product brochures were also collected to have an overview of companies manufacturing SPFHs and the different features of commercial harvesters. The following collected data underwent preliminary statistical processing for a functional and technical characterization of SPFHs:

- the wheel base and track width of the machine;

- the maximum platform height;

- the platform's maximum horizontal width the platform when the lateral platform (if any) are fully extended;

- the maximum weight allowed on the lateral platform.

Data were processed according to descriptive statistics using the Minitab 10.0 statistical software, State College, PA, USA [15]. 


\subsection{Experimental Activity in Open Field Conditions}

Field tests were carried out on four different SPFH models, hereafter labelled A, C, D, and E (Table 1). The vehicles were monitored while performing tasks under real operating conditions.

Table 1. Descriptive data of the tested SPFHs on operation in filed.

\begin{tabular}{cccccc}
\hline SPFH Label & Platform Type & Wheel Base (mm) & $\begin{array}{c}\text { Width Track }(\mathbf{m m}) \\
\text { Front/Rear }\end{array}$ & $\begin{array}{c}\text { Platform Height during } \\
\text { the Field Tests }(\mathbf{m m})\end{array}$ & Operation \\
\hline A & Single & 1700 & $1670 / 1690$ & 1200 & Fruit picking \\
C & Single & 2135 & $1600 / 1600$ & 2450 & Fruit picking \\
D & Double & 2240 & $1780 / 1780$ & 2450 & Fruit picking \\
E & Single & 2200 & $1680 / 1680$ & 2650 & Summer \\
pruning
\end{tabular}

SPFH A was also used to simulate field operations (lateral extension of the platform, machine transfer, fruit picking). During these tests the platform was raised to the maximum height (2900 $\mathrm{mm})$ whereas SPFHs C, D, and E were used for ordinary activities (fruit picking, bin loading, and unloading and summer pruning) only.

During field tests roll angles were recorded using an inertial measurement unit (IMU) and a GPS (DS-IMU1); additional data, such as georeferenced position, speed, and direction were also acquired. Other collected field data include the position and mass of the operators, bins and baskets. These data were subsequently used to define settings for laboratory tests. Field tests were carried out in apple and peach orchards, the main characteristics of which are reported in Table 2.

Table 2. Characteristics of the two fields where test have been carried out.

\begin{tabular}{ccccc}
\hline \multirow{2}{*}{ Species } & Grown Cultivars & Pruning Style & \multicolumn{2}{c}{ Tree Spacing (m) } \\
\cline { 4 - 5 } Apple & $\begin{array}{c}\text { Gala } \\
\text { Jeromine }\end{array}$ & Taille longue & 1 & 4 \\
\hline \multirow{2}{*}{ Peach } & $\begin{array}{c}\text { Big Top } \\
\text { Nectacross }\end{array}$ & Spindle & 1.5 & 4 \\
\hline
\end{tabular}

The apple trees are trained according to the Taille longue pruning system (Figure 1). The trees have an axial shape and a tendency to develop free-bearing (acrotony) summit branches; the fruit-bearing branches, bent below the horizontal and never shortened, are inserted along the entire central axis [16].

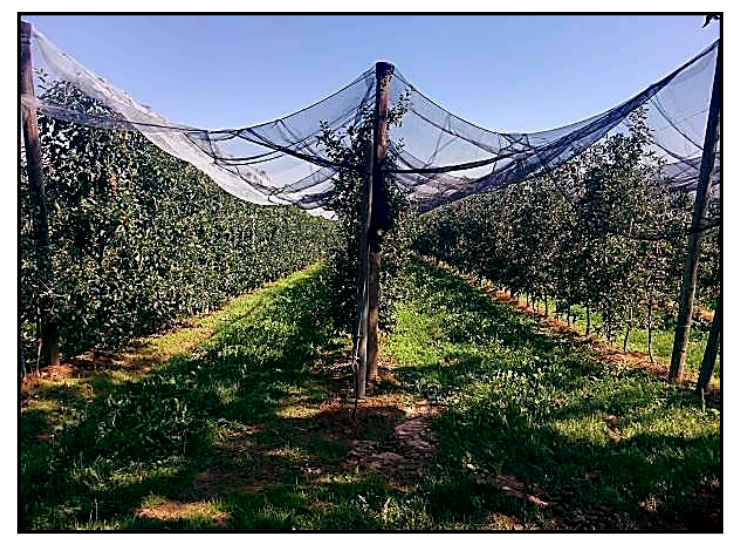

Figure 1. Tree spacing plantation layout of the apple orchard. 
The peach trees (Figure 2) are trained with the Fusetto (free spindle) system. The trees, 3.0-3.5 m tall, have a single vertical stem leader and are conical in shape; the central trunk has no permanent lower tier branches $[17,18]$. SPFHs are well suited for operation in the resulting hedgerows.

In all the apple and peach orchards there was hail netting in place. The nets covered the entire area above the tree tops (Figures 1 and 2).

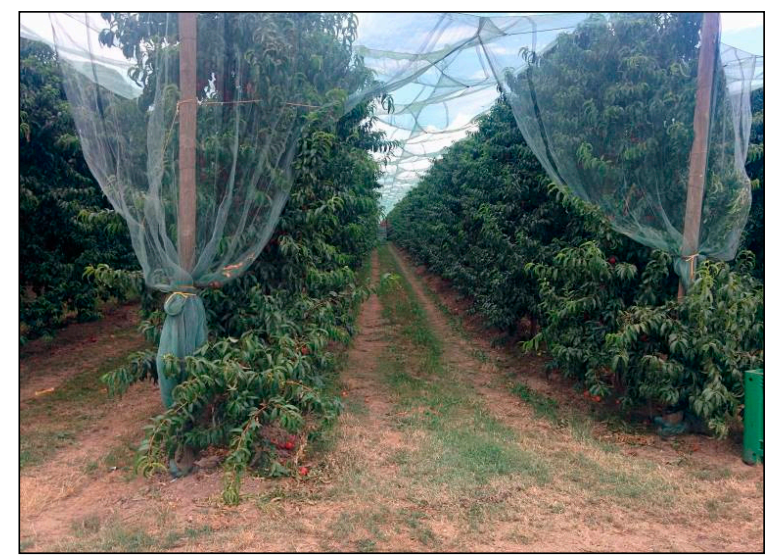

Figure 2. The peach orchard.

In the Big Top peach orchard, field assessment was carried out during fruit picking, with the platform at a height of $2.45 \mathrm{~m}$ and extending $0.35 \mathrm{~m}$ on each side, while in the Nectacross peach plots, data were collected during summer pruning (Figure 3). The platform was at a height of $2.65 \mathrm{~m}$ and the lateral platforms were extended by operators to $200-350 \mathrm{~mm}$. In both plots the ground between rows had a less than $1^{\circ}$ slope to allow for flood irrigation.

Surveys were carried out in late July 2016.

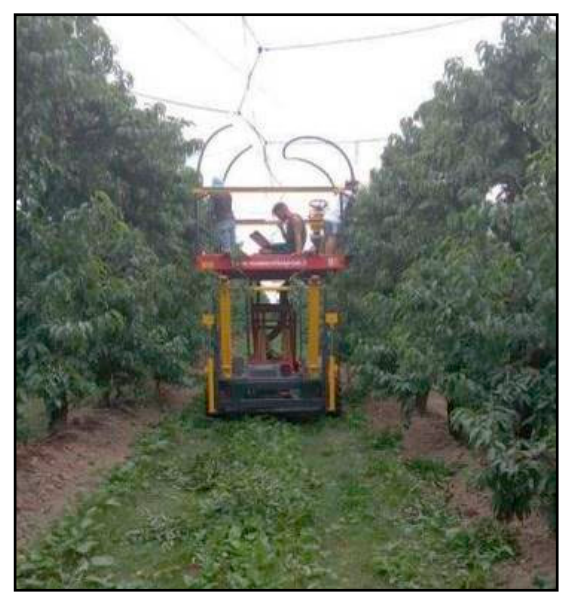

Figure 3. Recording of experimental data during summer pruning.

\subsection{Laboratory Tests}

Laboratory tests aimed to define an appropriate procedure to determine the centre of gravity and lateral stability of SPFHs.

Tests were carried out on two SPFHs (hereafter labelled A and B) the characteristics of which are summarized in Table 3. 
Table 3. Main characteristics of the SPFHs adopted for the laboratory tests.

\begin{tabular}{cccccccc}
\hline SPFH & Unit & Wheel-Base & $\begin{array}{c}\text { Tire Index } \\
\text { Radius }\end{array}$ & $\begin{array}{c}\text { Width-Track } \\
\text { (Front) }\end{array}$ & $\begin{array}{c}\text { Width-Track } \\
\text { (Rear) }\end{array}$ & $\begin{array}{c}\text { Maximum Platform } \\
\text { Height }\end{array}$ & $\begin{array}{c}\text { Maximum Lateral } \\
\text { Extension }\end{array}$ \\
\hline $\mathrm{A}$ & $\mathrm{mm}$ & 1700 & 360 & 1670 & 1690 & 2900 & 850 \\
$\mathrm{~B}$ & $\mathrm{~mm}$ & 1948 & 371 & 1653 & 1653 & 2650 & 750 \\
\hline
\end{tabular}

\subsubsection{Definition of the Machine Settings}

In order to set the laboratory experimental conditions, a standard operator and standard fruit bin dimensions and positions had to be defined. It was therefore necessary to define the mass, the CoG and the positioning on the SPFH of the masses simulating the operators and the fruit bin. The size and position of the bins and of the operators in the laboratory tests were defined on the basis of standard practice observed during field tests and of specifications from appropriate international standards $[19,20]$.

\subsubsection{SPFH Centre of Gravity Assessment}

Following the recommendation in ISO 16231-2, assessment of the centre of gravity was carried out on the two SFPHs in compliance with the ISO 789-6 "Agricultural tractors-Test procedures, Part 6: Centre of Gravity" standard [21,22] by measuring the variation of the mass at the ground after lifting one of the axles. The measurements were carried out using:

- a 16 t maximum capacity overhead crane (Demag Cranes Components Spa, Italy);

- a Fisco Solatronic EN 17 digital inclinometer (Solar Design Company, Machynlleth, UK) with $0.1^{\circ}$ resolution,

- four Argeo DFWKR force plates (Dini Argeo S.r.l., Spezzano di Fiorano Modenese (MO), Italy).

ISO 16231-2, ISO 789-6, ISO 22915-1 and UNI-EN 1459 recommend that the machine be equipped and adjusted ready for work with tanks filled at their proper operating levels. The only issue that remains open is the level of fuel in the tank, which must be considered in light of the stability it induces (e.g., UNI-EN 1459 and ISO 22915-1 recommend that fuel tank is full in case stability is thereby decreased). A simulation highlighted the impact of $40 \mathrm{~kg}$ of fuel on the vertical position of the CoG, when the vehicle's platform is at the maximum height, in 11-14 mm depending on the setting. In this study all the experimental tests were carried out with a full tank. The machine had no auxiliary equipment for bin loading/unloading; ballasts simulated the presence of operators on the platform and the tire pressure was set at the manufacturer's recommended value. The CoG's position was assessed by means of the double weight method: weights were first recorded with the machine standing with all four wheels on flat pavement and then with one axle lifted until it reached a $20^{\circ}$ inclination (Figure 4). On this occasion the wheelbase, the index radius of the rear wheel, and the front and rear track widths were also recorded.

The machines were tested with the platform completely lowered and with no mass on the platform (Setting " $L$ ") and in the setting with the platform at its maximum height and carrying different masses (" $\mathrm{H}$ " Settings). See Table 4 for the detailed scheme of the adopted $\mathrm{H}$ settings. 


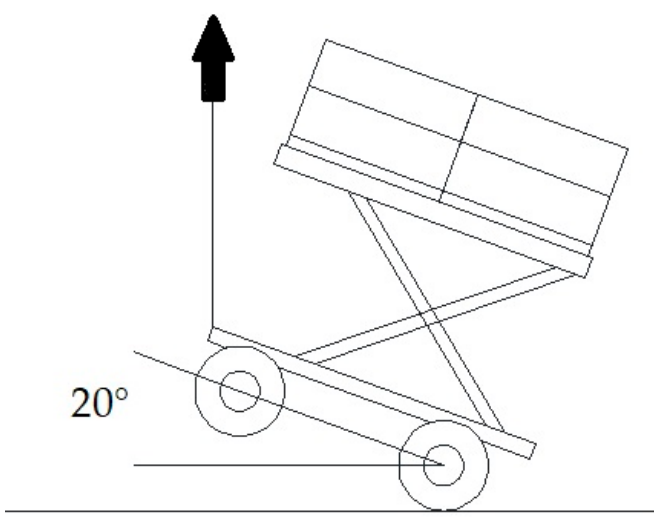

Figure 4. The double weight method (standing on the four wheels and with a $20^{\circ}$ inclination) was adopted for the assessment of the centre of gravity.

Table 4. Settings of the SPFHs during the CoG determination.

\begin{tabular}{ccccc}
\hline Setting Code & Lateral Extensions & $\begin{array}{c}\text { Weight on the } \\
\text { Platform (kg) }\end{array}$ & $\begin{array}{c}\text { Weight on the Upper } \\
\text { Lateral Extension (kg) }\end{array}$ & $\begin{array}{c}\text { Weight on the Sloped Down } \\
\text { Lateral Extension (kg) }\end{array}$ \\
\hline H0 & both completely retracted & 0 & 0 & 200 \\
\hline H1 & both fully extended & 400 & 0 & 200 \\
\hline H2 & $\begin{array}{c}\text { only the sloped down side } \\
\text { fully extended }\end{array}$ & 400 & 0 & 200 \\
\hline H3 & $\begin{array}{c}\text { only the sloped down side } \\
\text { fully extended }\end{array}$ & 0 & 0 & 0 \\
\hline L & both completely retracted & 0 &
\end{tabular}

\subsubsection{SPFH Stability Assessment}

The stability overturning angle (SOA) was assessed following ISO-16231 standards [22,23] by placing two SPFHs (hereafter labelled A and B) on a tilting platform and determining the angle in the lengthwise direction of the machine only. The detailed description of the testing procedure hereafter reported was taken from UNI ISO 22915-1 [24] and UNI EN 1459 [20]:

- the tilting platform was in continuous motion;

- $\quad$ the platform was inclined slowly and continuously;

- the angle was measured by means of a Fisco Solatronic EN 17 digital inclinometer (Solar Design Company, Machynlleth, UK) having a $0.1^{\circ}$ resolution;

- $\quad$ the platform did not undergo any significant deformation that might have affected results;

- tires were inflated to the manufacturer's recommended pressure;

- chains and ropes harnessed the machine, preventing it from overturning completely and from exiting the testing surface;

- the initial position of the machine on the testing surface was maintained using the parking brake and lateral constraints complying with ISO requirements $(10 \%$ of the wheel diameter up to a maximum height of $50 \mathrm{~mm}$ ).

The SPFHs were tested with the platform at the maximum height in the Hi settings presented in Table 4.

\section{Results}

This section reports the results of the performed analysis.

The results of the market survey are presented first. Field tests are then analysed to determine the most common operating conditions. Lastly, the paper reports the results of the rollover stability test using a tilting platform under the most common operating conditions and operators/fruit-bin settings. 


\subsection{Market Survey}

The survey of the Italian market identified 20 different firms producing a good 110 different SPFH models. The results are in accordance with the findings in an MSA (Mutualite sociale agricole) study revealing that most of the SPFH models in France are from Italian manufacturers [4]. Italy is, in fact, a world leader in agricultural and forestry machinery production, with large global and small local companies active in the sector [25].

Three groups of machines were defined on the basis of the track width, one of the parameters affecting machine stability the most: the first (narrower machines) includes tracks $1100 \mathrm{~mm}$ to $1200 \mathrm{~mm}$ wide; the second, intermediate group, includes machines with track widths ranging between 1201 and $1600 \mathrm{~mm}$, and the last group includes wider machines with track widths greater than $1600 \mathrm{~mm}$. Track widths are in relation to the intended use of the machine and depend mostly on the layout of the orchard. The maximum lateral extension of the platform is $500 \mathrm{~mm}$ for the narrow machines, $700-800 \mathrm{~mm}$ for the intermediate ones, and $1200 \mathrm{~mm}$ for the wider models, whereas the maximum height of the platform is $2300 \mathrm{~mm}$ for the narrow models, $2300-2700 \mathrm{~mm}$ for the intermediate ones, and 2700-3000 mm for wider machines. Descriptive statistics of the collected dataset are summarized in Figure 5.

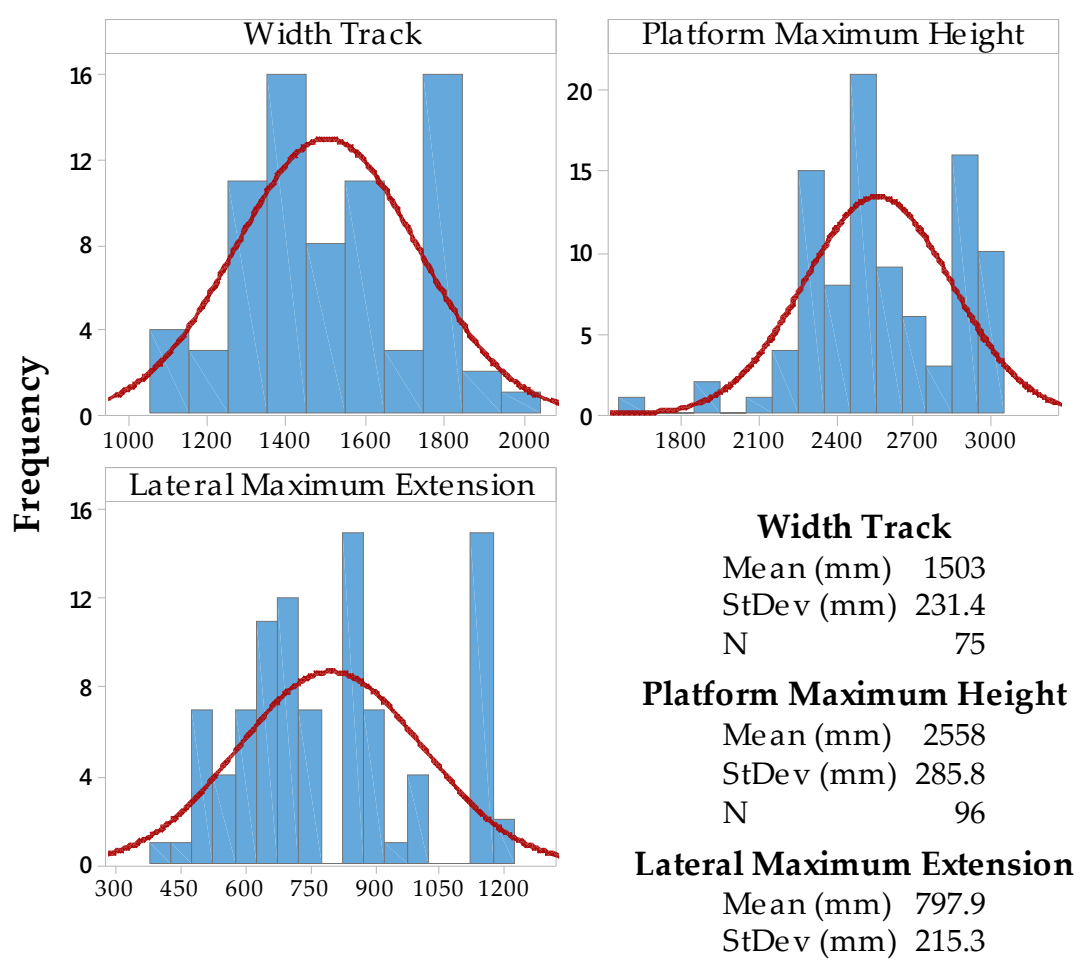

Figure 5. Descriptive statistics of the collected dataset.

Based on the characteristics of the 110 SPFHs it was decided that the models to be studied in laboratory conditions representing the worst case scenario should meet the following requirements:

- $\quad$ single platform without a self-levelling system

- $\quad$ extending structure that lifts the working platform up to $2900 \mathrm{~mm}$;

- at least $800 \mathrm{~mm}$ lateral extension of the working platform;

In addition, among the SPFHs having such characteristics, those with a narrower track width (up to $1700 \mathrm{~mm}$ ) were considered more suitable: the choice therefore fell on SPFH A, the characteristics of which are reported in Table 3. SPFH model B belongs to the same category and was selected for comparison in laboratory conditions: also its features are summarized in Table 3. 


\subsection{Experimental Activity in Open Field Conditions}

SPFH operational conditions during fruit picking and pruning are considered static because of the very slow forward speed. The SPFHs involved in the study were operating on a levelled grassy surface with less than $1^{\circ}$ longitudinal and lateral slopes. The mean value of the measured vehicle roll angles was $0.85^{\circ}$, with a maximum recorded value under all conditions of $2.9^{\circ}$. Data for the four SPFHs in operational conditions are summarized in Table 5.

Table 5. The measured roll angle of the tested SPFH during fruit picking and pruning.

\begin{tabular}{cccc}
\hline SPFH & Maximum Roll Angle $\left(^{\circ}\right)$ & Maximum Forward Speed $(\mathbf{k m} / \mathbf{h})$ & Measurement Time $(\mathbf{s})$ \\
\hline \multirow{3}{*}{$\mathrm{A}$} & 2.0 & 0.1 & 10 \\
& 1.8 & 1.1 & 52 \\
& 2.1 & 1.0 & 44 \\
& 1.2 & 0.9 & 42 \\
\hline \multirow{2}{*}{$\mathrm{C}$} & 2.7 & 2.1 & 191 \\
& 2.7 & 0.7 & 133 \\
& 2.9 & 0.4 & 120 \\
& 1.1 & 0.4 & 120 \\
$\mathrm{~N}$ & 0.7 & 0.3 & 107 \\
& 0.7 & 0.4 & 196 \\
$\mathrm{~N}$ & 0.7 & 0.2 & 92 \\
\hline \multirow{2}{*}{$\mathrm{E}$} & 1.6 & 0.5 & 65 \\
& 0.6 & 0.5 & 29 \\
\hline
\end{tabular}

Field tests revealed that during fruit picking operators normally work with different kinds of portable containers placed on the platform; these are filled directly and then placed at the centre of the platform for unloading. The estimated weight of these containers is $7-8 \mathrm{~kg}$. Under normal working conditions, operators stand on the platform facing the trees and with the tip of their shoes touching the safety edge of the lateral extension.

\subsection{Laboratory Tests}

\subsubsection{Definition of Machine Settings for the Laboratory Tests}

For the laboratory tests $100 \mathrm{~kg}$ was selected as the standard weight of the operator. The value comprises the 90-95 kg weight of the operators considered in ISO standards $[19,20]$ and the $7-8 \mathrm{~kg}$ basket that operators use during fruit picking. Note that SPFH user manuals consider a mass weighing $80-120 \mathrm{~kg}$. Considering the weight of the standard operator, the CoG is $1000 \mathrm{~mm}$ above the platform [24].

The "standard operator" considered in the tests has the following characteristics:

- $\quad$ weight: $100 \mathrm{~kg}$

- height of CoG: $1000 \mathrm{~mm}$ above the floor of the platform;

- lateral position of the CoG: $100 \mathrm{~mm}$ from the edge of the lateral extension; and

- longitudinal position of the CoG: in the hypothesis that there are two operators on the platform, they are supposed to stand $1300 \mathrm{~mm}$ from each other and in the middle of the platform.

When picking fruit, the bins are placed on specific rails at the centre of the platform. Bins have standard dimensions. Bins with the following characteristics were selected for use in laboratory tests:

- external dimension: $1200 \times 1100 \times 630 \mathrm{~mm}$;

- internal dimensions: $1100 \times 1010 \times 475 \mathrm{~mm}$;

- capacity: $0.56 \mathrm{~m}^{3}$; and

- weight when empty: $37 \mathrm{~kg}$. 
The capacity in $\mathrm{kg}$ depends on the fruit. Table 6 reports the weight capacity for different products.

Table 6. Mass capacity of the selected fruit bin.

\begin{tabular}{cc}
\hline Product & Capacity (kg) \\
\hline Apples & 260 \\
Peaches & 310 \\
Oranges & 310 \\
Carrots & 340 \\
Olive & 350 \\
Tomatoes & 360 \\
Potatoes & 360 \\
\hline
\end{tabular}

The dimensions of the mass simulating the fruit bin placed on the platform are as follows:

- $\quad$ weight: $400 \mathrm{~kg}$;

- height of the CoG: $400 \mathrm{~mm}$ above the floor of the platform; and

- position: at the centre of the platform.

Figure 6 illustrates the position of the standard operators and bin in laboratory tests for assessing the CoG.

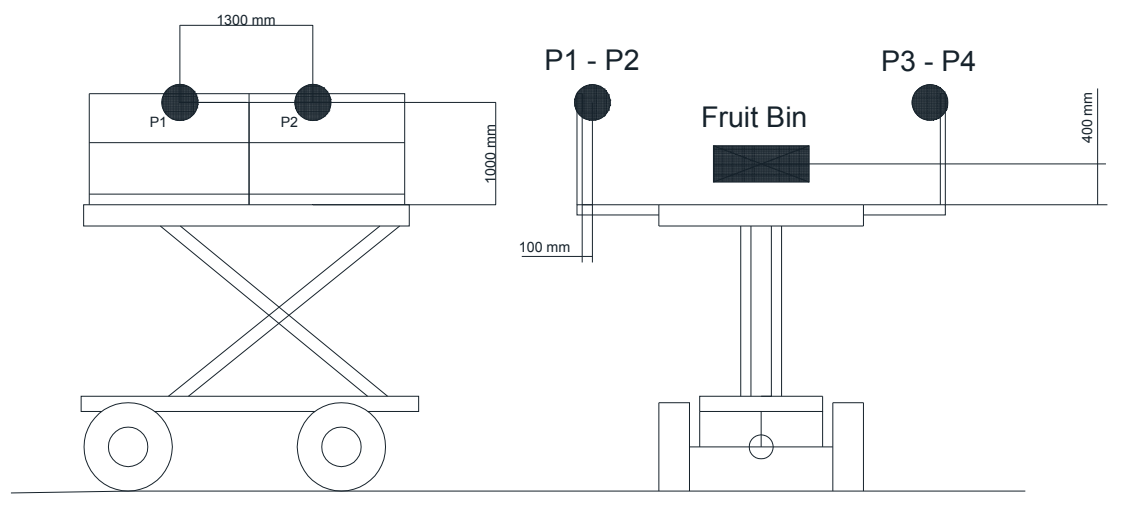

Figure 6. Scheme of the masses on the platform during CoG assessment (P1, P2, P3, and P4 are the operators).

Figure 7 illustrates the position of standard operators and the bin during the lateral stability tests, whereas Table 4 reports the test setting ( $\mathrm{H} 0-\mathrm{H} 3)$.

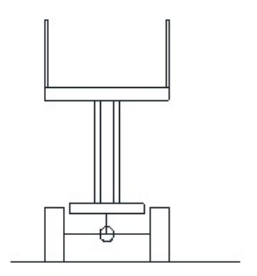

H0

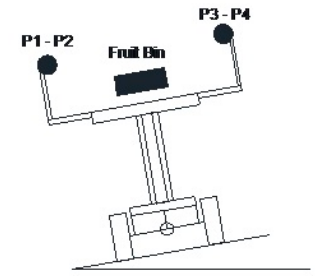

H1

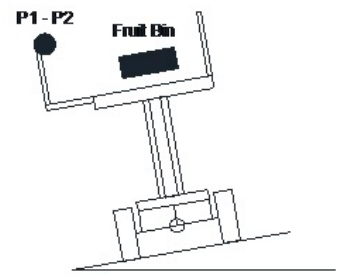

$\mathrm{H} 2$

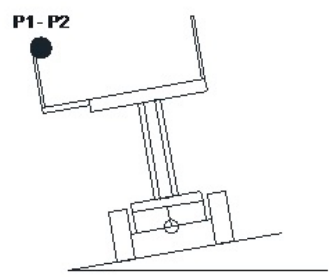

H3

Figure 7. Settings during lateral stability assessment tests (front view).

\subsubsection{Centre of Gravity Assessment}

The coordinates of the CoG resulting from the ISO 16231 double weight method for two SPFHs (A and B) are reported in Table 7 for the different test settings (see Table 4). 
Table 7. Centre of gravity coordinates $(\mathrm{mm})$ in the two tested SPFHs.

\begin{tabular}{ccccccc}
\hline \multirow{2}{*}{ Settings } & \multicolumn{3}{c}{$\mathbf{A}$} & \multicolumn{3}{c}{$\mathbf{B}$} \\
\cline { 2 - 7 } & $\mathbf{X}^{\mathbf{a}}$ & $\mathbf{Y}^{\mathbf{b}}$ & $\mathbf{Z}^{\mathbf{c}}$ & $\mathbf{X}^{\mathbf{a}}$ & $\mathbf{Y}^{\mathbf{b}}$ & $\mathbf{Z}^{\mathbf{c}}$ \\
\hline H1 & 671 & 5 & 1994 & 805 & 46 & 1665 \\
H2 & 677 & 134 & 1904 & 795 & 181 & 1621 \\
H3 & 687 & 140 & 1692 & 772 & 206 & 1419 \\
H0 & 703 & 10 & 1540 & 780 & 62 & 1256 \\
L & 611 & 10 & 701 & 823 & 55 & 492 \\
\hline
\end{tabular}

a Along the transversal plane of the vehicle, from the rear axle positive values frontward; ${ }^{\mathrm{b}}$ along the median plane of the vehicle, from the centre line, positive values rightward; ${ }^{c}$ along the vertical axis of the vehicle, from ground.

Tests on both SPFHs reveal that height of the CoG ( $\mathrm{Z}$ axis) clearly depends on the masses (operators and bins) and their position on the raised platform. When the platform is fully extended, the $\mathrm{CoG}$ increases from $\mathrm{H} 0$ (no masses) to $\mathrm{H} 3$ (2 operators) to $\mathrm{H} 2$ (two operators on one side and a bin) and reaches the maximum value for $\mathrm{H} 1$ (four operators and a bin). The CoG shows a $~ 30 \%$ increase from $\mathrm{H} 0$ to $\mathrm{H} 1$. The presence of additionally masses on the platform has little effect on the longitudinal position ( $\mathrm{X}$ axis) of the $\mathrm{CoG}$, whereas it greatly affects the transversal position ( $\mathrm{Y}$ axis) of the CoG in settings $\mathrm{H} 3$ (2 operators on one side) and $\mathrm{H} 2$ (two operators on one side, plus a bin).

\subsubsection{SPFH Lateral Stability Assessment}

SPFHs A and B (see Table 3) were tested at the tilt table. Both SPFHs have one pivoting axle. $\mathrm{SPFH}$ " $\mathrm{A}$ " has a swivelling suspension without any limiting device. This means that the pivoting axle is free to rotate through a wide range of angles with respect to the vehicle chassis (i.e., until the axle/tyres touch the chassis). SPFH " $\mathrm{B}$ ", instead, has the pivoting axle equipped with springs that limit swivelling of the suspension (self-levelling system).

For both vehicles, the first wheel to lose contact with the test bench during the tilting test is the one of the axle fixed to the frame on the upslope side of the vehicle. There are two phases of roll-over: initial detachment of the wheel from the tilted surface and subsequent complete detachment (vehicle rollover).

In the absence of a self-levelling mechanism for the pivoting axle, due to the inertia of the vehicle, detachment of the first wheel may lead to a complete roll-over of the machine, even if the angle of inclination remains constant. In contrast, in the presence of a limiting device for the pivoting axle, rollover stability of the vehicle is not compromised even if one wheel is detached from the ground. In the case of SPFH "B", although one tyre initially detached from the floor of the tilting platform, the pivoting axle touched the frame and stopped the tilting motion by acting as a damping system: complete loss of lateral stability only occurred when the inclination angle was increased further. In contrast, because SPFH " $\mathrm{A}$ " was not fitted with a damping system, initial detachment was followed by complete loss of lateral stability.

The results of the rollover tests on SPFH " $\mathrm{A}$ " and "B" at the tilting platform are reported in Table 8 and compared with SOAs calculated in accordance with ISO 16231-2. Although such standard is not applicable on SPFHs, this was done to check how much the output of the algorithm of the standard fits the overturning angles assessed experimentally. 
Table 8. Roll-over angles $\left(^{\circ}\right)$ of the two tested SPFH.

\begin{tabular}{|c|c|c|c|c|c|c|}
\hline \multirow[b]{2}{*}{ Setting Code } & \multicolumn{2}{|c|}{$\mathbf{A}$} & \multicolumn{4}{|c|}{ B } \\
\hline & $\mathrm{I}^{1}$ and $\mathrm{II}^{2}$ & $\operatorname{SOA}^{3} I^{1}$ & $\mathrm{I}^{1}$ & $\operatorname{SOA}^{3} I^{1}$ & $\mathrm{II}^{2}$ & $\mathrm{SOA}^{3} \mathrm{II}^{2}$ \\
\hline $\mathrm{HO}$ & 20.0 & 20.7 & 20.3 & 23.3 & 26.3 & 33.5 \\
\hline $\mathrm{H} 1$ & 14.8 & 16.0 & 16.1 & 17.3 & 21.7 & 27.0 \\
\hline $\mathrm{H} 2$ & 11.9 & 12.9 & 12.2 & 13.0 & 18.7 & 23.7 \\
\hline H3 & 13.3 & 14.3 & 13.9 & 14.4 & 20.9 & 25.9 \\
\hline
\end{tabular}

${ }^{1}$ Angle of first detachment; ${ }^{2}$ angle of complete roll-over; ${ }^{3}$ based on ISO 16231 calculation.

From such table it can be noticed that SOA I and SOA II values (that can be compared with the values the ISO 16231-2 defines $\alpha$ and $\sigma$ ) differ from measured ones of about $1^{\circ}$ and $5^{\circ}$.

Lateral stability tests reveal that, although the two different SPFH models have platforms with different maximum vertical and lateral extensions, they have very similar angles of first detachment, but different angles of lateral stability. In vehicles equipped with pivoting axles, but no device acting as a dumping system, the inertia of the vehicle affects the roll-over dynamics. The conditions most likely leading to loss of lateral stability are those where the lateral extension on the downslope of the SPFH is fully extended and carries two operators with the fruit bin in the middle of the platform (setting H2). When there is no bin in the middle of the platform, loss of lateral stability occurs at slightly higher lateral inclinations (setting H3. According to manufacturer technical specifications, the fruit bin is considered a stabilizing factor when the SPFH is equipped with a lateral self-levelling platform. This means that the condition most likely to lead to a loss of lateral stability is that without a bin (setting H3).

Test results suggest that settings $\mathrm{H} 2$ and $\mathrm{H} 3$ are the ones mostly suitable for use in SPFH lateral stability testing.

\section{Discussion}

SPFHs are machines commonly adopted in orchards farms to carry out many operations efficiently. There are many different models manufactured by a large number of firms for use in different orchard settings.

Generally operated at reduced speeds on flat surfaces, SPHFs can lose stability, likely resulting in lateral rollover. This represents a serious risk for operators on the platform, as they do not have any means of protection.

Market survey results reveal that there is a lack of data both on the operating conditions of these machines and on SPHF rollover angles: although such information is reported in user manuals, there is no standard approach to measurement, and manufacturers adopt different methods and safety coefficients. It is, therefore, impossible to establish a reference rollover angle.

Experimental activity carried out in open field conditions (on perfectly levelled ground) provided information on the average $\left(0.85^{\circ}\right)$ and maximum $\left(2.9^{\circ}\right)$ roll angle experienced by such machines. It also highlighted the actual operating conditions that any standard test should take into consideration (e.g., placement and weight of operators and bins, if any). Testing was used to check SPFH compliance with international standards for $\mathrm{CoG}$ and rollover angles in agricultural machinery; it also allowed the definition of specific test settings for SPFHs.

The lowest rollover angle was recorded for harvesters working with the lateral platform fully extended, operators on one side only and a bin placed in the middle of the platform; as for self-levelling SPFHs, the stabilizing effect of the bin declared by some manufacturers should be carefully considered because it is not supported by any studies.

Laboratory investigation revealed the importance of the setting in which the vehicle is tested, especially the masses simulating the weight and position of operators and the fruit bin on the platform. The study revealed the influence of damping systems in vehicles equipped with pivoting axles: 
the presence of a swivel limiting device on the swivelling axle restricts swivelling of the axle prior to the overturning of the machine.

The study identified a reliable procedure, consistent with the real operating condition of these vehicles, for assessing lateral stability under standard testing conditions enabling comparison.

Acknowledgments: The study was carried out within the "PROMOSIC" project, within the framework of the "BRIC 2015" call funded by INAIL (Italian National Institute for Insurance against Accidents at Work). The authors acknowledge the role of Ivan Carminati, Gianluigi Rozzoni, Alex Filisetti, and Elia Premoli for their valuable help in carrying out the measurements.

Author Contributions: Maurizio Cutini and Vincenzo Laurendi conceived the experiments; Maurizio Cutini, Carlo Bisaglia, and Edoardo Sabbioni designed the experiments; Maurizio Cutini, Massimo Brambilla, and Eugenio Cavallo performed the experiments; Maurizio Cutini, Massimo Brambilla, Stefano Melzi, Edoardo Sabbioni, and Michele Vignati analyzed the data; Maurizio Cutini, Carlo Bisaglia, and Eugenio Cavallo contributed materials tools; and Maurizio Cutini, Massimo Brambilla and Eugenio Cavallo drafted the manuscript.

Conflicts of Interest: The authors declare no conflict of interest. The founding sponsors had no role in the design of the study; in the collection, analyses, or interpretation of data; in the writing of the manuscript; and in the decision to publish the results.

\section{References}

1. EN 16952-2016 Agricultural Machinery-Rough-Terrain Work Platforms for Orchard's Operations (WPO)—Safety. Draft Edition: 1 February 2016. Available online: https://shop.austrian-standards.at (accessed on 7 June 2017).

2. Coppock, G.E.; Jutras, P.J. An investigation of the mobile picker's platform approach to partial mechanization of citrus fruit picking. Proc. Fla. State Hort. Soc. 1960, 73, 258-263.

3. Fathallah, A.F. Musculoskeletal disorders in labor-intensive agriculture. Appl. Ergon. 2010, 41, 738-743. [CrossRef] [PubMed]

4. MSA (2015) La sécurité des Plates-Formes de Récolte et de Taille en Arboriculture. Available online: http:/ / www.msa.fr (accessed on 7 June 2017).

5. Cavallo, E.; Görücü, S.; Murphy, D.J. Perception of side rollover hazards in a pennsylvania rural population while operating an all-terrain vehicle (ATV). Work 2015, 51, 281-288. [CrossRef] [PubMed]

6. Görücü, S.; Cavallo, E.; Murphy, D.J. Perceptions of tilt angles of an agricultural tractor. J. Agromed. 2014, 19, 5-14. [CrossRef] [PubMed]

7. Franceschetti, B.; Lenain, R.; Rondelli, V. Comparison between a rollover tractor dynamic model and actual lateral tests. Biosyst. Eng. 2014, 127, 79-91. [CrossRef]

8. Vidoni, R.; Bietresato, M.; Gasparetto, A.; Mazzetto, F. Evaluation and stability comparison of different vehicle configurations for robotic agricultural operations on side-slopes. Biosyst. Eng. 2015, 129, 197-211. [CrossRef]

9. Wang, W.; Wu, T.; Hohimer, C.J.; Mo, C.; Zhang, Q. Stability analysis for orchard wearable robotic system. IFAC PapersOnline 2016, 49, 61-65. [CrossRef]

10. Jung, D.; Jeong, J.; Woo, S.M.; Jang, E.; Park, K.; Son, J. A study on the stability of a vehicle with lifting utility. Adv. Mater. Res. 2013, 753-755, 1169-1174. [CrossRef]

11. Myers, M.L. Ride-On Lawnmowers. The hazards of overturning. Prof. Saf. 2009, 54, 52-63. Available online: www.asse.org (accessed on 7 June 2017).

12. Liu, J.; Ayers, P.D. Off-road vehicle rollover and field testing of stability index. J. Agric. Saf. Health 1999, 5, 59-72. [CrossRef]

13. Molari, G.; Badodi, M.; Guarnieri, A.; Mattetti, M. Structural strength evaluation of driver's protective structures for self-propelled agricultural machines. J. Agric. Saf. Health 2014, 20, 165-174. [CrossRef] [PubMed]

14. Shulruf, B.; Balemi, A. Risk and preventive factors for fatalities in all-terrain vehicle accidents in New Zealand. Accid. Anal. Prev. 2010, 42, 612-618. [CrossRef] [PubMed]

15. Minitab 17 Statistical Software. Minitab, Inc.: State College, PA, USA, 2010. Available online: www.minitab.com (accessed on 7 June 2017).

16. Diemoz, M.; Vittone, G.; Pantezzi, T. Possibili evoluzioni nella potatura del melo (Potential improvements in apple tree pruning). Inf. Agrar. 2003, 59, 77-78. 
17. Bargioni, G.; Loreti, F.; Pisani, P.L. Performance of peach and nectarine in a high density system in Italy. HortScience 1983, 18, 143-146.

18. Corelli-Grappadelli, L.; Marini, R.P. Orchard Planting Systems. In The Peach: Botany, Production and Uses; Layne, D.R., Bassi, D., Eds.; CAB International: Oxfordshire, UK, 2008; ISBN 978-1-84593-386-9.

19. Industrial Trucks. Verification of Stability. Part 2: Counterbalanced Trucks with Mast; UNI ISO 22915-1/2:2008; International Organization for Standardization: Geneva, Switzerland, 2008.

20. Safety of Industrial Trucks—Self Propelled Variable Reach Trucks.9-6 (Agricultural Tractors-Test ProceduresPart 6: Centre of gravity); UNI EN 1459:2010; UNI EN: Milano, Italy, 2010.

21. Agricultural Tractors-Test Procedures, Part 6: Centre of Gravity Standard; ISO 789-6; International Organization for Standardization: Geneva, Switzerland, 1982.

22. Self-Propelled Agricultural Machinery-Assessment of Stability-Part 1: Principles; ISO 16231-1:2013; International Organization for Standardization: Geneva, Switzerland, 2013.

23. Self-Propelled Agricultural Machinery—Assessment of Stability_Part 2: Determination of Static Stability and Test Procedures; ISO 16231-2:2015; International Organization for Standardization: Geneva, Switzerland, 2015.

24. Industrial Trucks. Verification of Stability. Part 1: General; UNI ISO 22915-1/1:2008; International Organization for Standardization: Geneva, Switzerland, 2008.

25. Cavallo, E.; Ferrari, E.; Coccia, M. Likely technological trajectories in agricultural tractors by analysing innovative attitudes of farmers. Int. J. Technol. Policy Manag. 2015, 15, 158-177. [CrossRef]

(C) 2017 by the authors. Licensee MDPI, Basel, Switzerland. This article is an open access article distributed under the terms and conditions of the Creative Commons Attribution (CC BY) license (http://creativecommons.org/licenses/by/4.0/). 